\title{
$\mathrm{SNS}$ 의 이용동기와 커뮤니케이션 행동에 관한 연구 \\ 김형석 ${ }^{*}$ \\ ${ }^{1}$ 청운대학교 광고홍보학과
}

\section{A Study on Use Motivation of SNS and Communication Behavior}

\author{
Hyung-Suk Kim ${ }^{1}$ \\ ${ }^{1}$ Department of Advertising and Public Relations, Chungwoon University
}

\begin{abstract}
요 약 본 연구의 목적은 SNS 이용동기가 이용자들의 커뮤니케이션 활동성과 SNS를 통한 소통에 대한 몰입 또는 이해도, 즉 미디어 인게이지먼트에 어떠한 영향을 미치는가를 살펴보기 위한 것이다. 본 연구의 주요 연구결과는 다 음과 같다. 첫째, 탐색적 요인분석을 통한 SNS 이용동기 측정항목에 대한 항목의 정화 결과, 세 가지 이용동기 요인 이 추출되었으며, 각각의 요인은 정보지식획득동기(IKAM), 소통관계유지동기(CRMM), 의견정보제시동기(OIPM)로 나 타났다. SNS 이용동기는 일반적으로 남성이 여성보다 다소 높았으며, 소통관계동기에서는 성별간 유의한 차이가 나 타났다. 둘째, SNS 이용동기 중 소통관계유지동기와 의견정보제시동기는 이용자의 커뮤니케이션 활동성에 통계적으로 유의하게 정적인 영향을 미치는 것으로 나타났다. 셋째, SNS 이용동기 중 정보지식획득동기와 소통관계유지동기는 $\mathrm{SNS}$ 를 통한 소통의 몰입과 이해도인 미디어 인게이지먼트에 긍정적인 영향을 미치는 것으로 나타났다.
\end{abstract}

\begin{abstract}
The purpose of this study is to explore how use motivation of SNS influences communication activity and SNS media engagement. The major findings are as follows.

First, three Factors are identified from the result of scale purification through exploratory factor analysis(EFA) on use motivation of SNS. Three factors of SNS use motivation are information/knowledge acquisition motivation (IKAM), communication/relationship maintaining motivation(CRMM), opinion/information presenting motivation(OIPM). It is found that a significant difference on CRMM between sex. Second, CRMM and OIPM are statistically significant to communication activity. Third, IKAM and CRMM are statistically significant to SNS media engagement.
\end{abstract}

Key Words : SNS, Use Motivation, Communication Activity, Media Engagement

\section{1. 서론}

전 세계적으로 트위터, 페이스북과 같은 $\mathrm{SNS}$ (Social Network Service)를 통한 커뮤니케이션의 이용 및 가치는 스마트폰의 활성화와 더불어 점점 더 높아지고 있다. $\mathrm{SNS}$ 를 통한 커뮤니케이션은 개인적 관계를 넘어서, 조직 과 개인 간 소통 채널로 활용되어지고 있다. 이제 SNS를 이용한 커뮤니케이션은 정치, 경제, 기업뿐만 아니라 사 회 전반에 걸쳐 그 중요성과 영향력이 증대되고 있는 실 정이다. 이러한 맥락에서 볼 때, SNS을 이용한 소통의 참
여와 활용에 대한 기업 및 조직의 관심은 매우 높아질 수 밖에 없는 상황이다. 이제 SNS는 기업 또는 조직의 필수 적인 커뮤니케이션 도구 중 하나로 자리매김하고 있다. 2010년 김형석·유현중[1]은 우리나라 기업 $\mathrm{CEO}$ 들의 트 위터 메시지와 전략을 유형별로 분석하여 제시한 바 있 다. 이후 학계에서는 기업 또는 마케팅 커뮤니케이션 관 점에서 SNS를 접근하기 위한 연구들이 꾸준히 시도되고 있는 상황이다.

본 연구에서는 현재 SNS의 주 이용자라고 볼 수 있는 대학생들을 대상으로 $\mathrm{SNS}$ 의 이용동기는 어떠한 차원으

*교신저자 : 김형석(kennyg@chungwoon.ac.kr)

접수일 12년 01월 27일수정일 12년 02월 08일

게재확정일 12 년 02 월 10 일 
로 구분할 수 있는지, 또한 성별에 따라 SNS의 이용동기 에 어떠한 차이가 있는지를 살펴보고자 하였다. 더 나아 가 SNS 이용동기 요인이 커뮤니케이션 활동성, 미디어 인게이지먼트에 어떻게 영향을 미치는가를 살펴보고자 하였다. 이를 통해 기업 커뮤니케이션 관점에서 SNS 이 용자의 이용동기와 커뮤니케이션 행동의 특징을 이해하 고 향후 $\mathrm{SNS}$ 를 활용한 커뮤니케이션의 접근방향에 대한 함의를 제공하고자 하였다.

\section{2. 연구방법론}

\section{1 연구방법과 표본의 특성}

본 연구는 2011년 11월 서울과 충남 소재의 대학생 SNS 이용자들 200 명을 대상으로 한 자기기입식 설문조 사로 진행되었다. 이 중에서 불성실 응답 설문지로 판단 되거나 조사항목이 누락된 설문지는 최종분석에서 제외 하였다.

표본의 특성을 살펴보면 남성이 $43.6 \%$, 여성이 $56.4 \%$ 로 여성이 다소 많은 것으로 나타났다. 응답자들의 SNS 이용 행태를 분석한 결과, 페이스북 이용자가 $83.6 \%$ 로 가장 많았고, 트위터 이용자는 $37.3 \%$, 미투데이 이용자가 $7.3 \%$ 등으로 나타났다. 응답자들 중에서 기업과 $\mathrm{SNS}$ 를 통해 소통하고 있는 사람은 $27.3 \%$, 기업 $\mathrm{CEO}$ 와 $\mathrm{SNS}$ 를 통해 소통하고 있는 사람은 $9.1 \%$ 로 나타났다. 응답자들 의 주당 평균 SNS 이용시간은 3.43 시간으로 나타났다. 한편 한 주를 기준으로 정보성 글쓰기와 대화성 글쓰기 의 빈도를 분석한 결과, 정보성 글쓰기는 주당 평균 7.3 회로 나타났으며 대화성 글쓰기는 15.37회로 나타났다. 표본의 특성을 종합하면, 응답자들은 트위터보다 페이스 북을 주로 이용하고 있는 것으로 나타나 본 연구의 연구 결과는 페이스북의 이용동기와 이와 관련된 커뮤니케이 션 행동의 관점이 반영된 것으로 바라보는 것이 바람직 하다고 판단된다. $\mathrm{SNS}$ 를 통한 커뮤니케이션은 정보성 보 다 대화성 소통 경향이 두드러지는 것으로 나타났다.

\subsection{SNS 이용동기}

Rubin[2]의 미디어 이용동기 연구에서 이용과 충족 이 론은 미디어 선택과 이용을 위한 커뮤니케이션 행동은 목표 지향적이고, 의도적이며, 동기가 있으며 필요나 욕 구를 만족시키기 위한 자발적 의지를 가진다는 것이다. 이러한 이유로 인하여 새로운 미디어가 등장하게 되면 미디어 이용동기를 확인하기 위한 접근법으로서 이용과 충족 이론이 활용되고 있다.
소셜미디어의 주된 이용 계기로는 정보습득이나 관계 유지, 정보나 일상 기록 및 저장, 새로운 사람과 관계 맺 기 등의 여러 동기들이 존재한다.최근 마이크로블로그 및 $\mathrm{SNS}$ 이용 동기에 관한 선행연구들을 살펴보면, 전통적 이용동기 외에 트위터에서 관찰되는 사회참여나 여론 및 팔로워 그룹 형성 등의 새로운 이용동기들이 발견되고 있으며, 집단별로 다른 이용동기를 나타낸다는 결과들이 제시되고 있다. 김남이·이수범[3]은 소셜미디어의 이용동 기를 분석하기 위해 선행연구에 사용된 요인들을 수정 및 보완하여 총 21 개의 문항을 사용한 바 있다. 이 연구 에서 $\mathrm{SNS}$ 는 정보형, 관계형, 유희형, 보상형으로 구분된 4 개의 요인들이 나타났다. 윤승욱[4]의 최근 연구에서는 총 22개의 문항을 사용하여 정보추구 동기, 사회적 영향 동기, 습관적 오락 동기, 인적 네트워크 동기로 구분된 4 개의 요인을 도출한 바 있다. 심홍진·황유선[5]은 정보교 환을 위한 사회이슈참여, 상호작용을 바탕으로 팔로워 그 룹형성, 편리한 소통기능, 정보전달의 용이성, 휴식 및 오 락, 사적 기록 공간, 140 자 글쓰기 유용성 등 7 가지 동기 요인을 도출해낸 바 있다.

본 연구에서는 기업의 $\mathrm{SNS}$ 를 활용한 소통 접근방안 을 살펴보기 위한 탐색적 연구의 성격을 가지고 있다. 이 러한 점을 반영하여 $\mathrm{SNS}$ 의 이용동기 측정항목을 도출하 고 요인분석을 통해 이를 정화하여 최종 분석에 사용하 고자 하였다. 이를 위해 선행연구에서 공통적으로 사용되 고 있는 소셜미디어 관련 이용동기 요인과 측정문항들을 포괄적이고 상호 배타적인 관점에서 선별하였다. 결과적 으로 본 연구에서는 $\mathrm{SNS}$ 이용동기 측정을 위해 4가지 하 부요인과 요인별로 6 개의 측정 문항을 도출하였다. $\mathrm{SNS}$ 이용동기 측정도구의 요인분석결과와 항목정화 결과는 아래의 표 1 에 제시되었다.

\section{3 요인분석을 통한 SNS 이용동기 측정 항 목의 정화 및 신뢰도 분석결과}

본 연구에서는 $\mathrm{SNS}$ 이용동기 측정문항을 정화하기 위 하여 이용동기에 대한 응답결과에 대하여 탐색적 요인분 석(EFA)을 반복적으로 실시하였다. 자료의 요인분석 적 합도 검증결과, $\mathrm{KMO}$ 표본적합도(MSA)에서 $\mathrm{KMO}$ 측도 가 .6이상인 .738로 나타났으며, Bartlett의 구형성 검증 또한 유의하게 나타나 $(\mathrm{x} 2=908.024, \mathrm{df}=276, \mathrm{p}=.000)$, 이에 주성분분석 방법, Kaiser 규칙(eigen value 기준: 1), 그리 고 Varimax 회전의 방식으로 탐색적 요인분석을 실시하 였다. 김병희·한상필[6]의 연구를 참고로 하여 측정항목 의 정화는 요인적재값 .50 미만 항목 제외, 요인적재값 .50 이상이나 다른 요인에 대한 요인적재값 .40 이상 항 
[표 1] SNS 이용동기에 대한 탐색적 요인분석 결과

[Table 1] Result of Exploratory Factor Analysis on Use Motivation of SNS

\begin{tabular}{|c|c|c|c|c|c|}
\hline 요인명 & 질문 문항 & 요인1 & 요인2 & 요인3 & $\begin{array}{l}\text { Reliability } \\
(\alpha)\end{array}$ \\
\hline \multirow{3}{*}{$\begin{array}{l}\text { 정보지식 } \\
\text { 획득동기 }\end{array}$} & 새로운 아이디어, 정보, 콘텐츠를 얻기 위해서 & .796 & & & \multirow{3}{*}{.733} \\
\hline & 전문적인 지식과 중요한 정보를 얻을 수 있고, 공유하기 위해 & .836 & & & \\
\hline & 사회문제에 관한 다양한 해석과 설명을 접할 수 있기 때문에 & .737 & & & \\
\hline \multirow{3}{*}{$\begin{array}{l}\text { 소통관계 } \\
\text { 유지동기 }\end{array}$} & 다른 사람들과 잘 어울릴 수 있기 위해 & & .788 & & \multirow{3}{*}{.667} \\
\hline & 다른 사람들과 소통하고 인간적 소통 관계를 맺기 위해 & & .761 & & \\
\hline & 일상에서 벗어나고 기분전환을 위해 & & .741 & & \\
\hline \multirow{2}{*}{$\begin{array}{l}\text { 의견정보 } \\
\text { 제시동기 }\end{array}$} & 나의 의견을 신속하고 명료하게 전달하기 위하여 & & & .815 & \multirow{2}{*}{.720} \\
\hline & 조언이나 정보가 필요한 다른 사람들을 돕기 위해 & & & .886 & \\
\hline \multirow{3}{*}{$\begin{array}{c}\text { 탐색적 } \\
\text { 요인분석 } \\
\text { 최종결과 }\end{array}$} & 고유값(eigen value) & 2.864 & 1.428 & 1.113 & \\
\hline & 설명 총 분산(\%) & 35.801 & 17.844 & 13.911 & \\
\hline & 누적 총 분산(\%) & 35.801 & 53.645 & 67.557 & \\
\hline
\end{tabular}

목 제외, 단일 항목으로 구성된 요인의 항목 제외, 그리고 최종 요인 구성에서 신뢰도를 만족하지 못하는 항목 제 외 등의 규칙을 따랐다. 그 결과, 최초 7개 요인에서 총 6 회의 탐색적 요인분석 반복 실시 후 표 1처럼 최종적으 로 3 개의 요인이 추출되었다. 요인분석을 통해 도출된 3 개 요인의 이름은 각 문항에 대한 면밀한 검토 후에 정보 나 지식의 획득과 공유를 위한 동기인 [정보지식획득동 기], 다른 사람들과 어울리고 소통하기 위한 동기인 [소 통관계유지동기], 그리고 다른 사람에게 의견이나 정보를 제시하고자 하는 [의견정보제시동기]로 명명하였다. 세 가지 요인은 SNS 이용동기에 대하여 약 $68 \%$ 의 설명력을 가지는 것으로 나타났다. 이와 관련된 본 연구의 연구문 제는 다음과 같다.

<연구문제 1> 성별에 따라 SNS의 이용동기에 어떠한 차이가 있는가?

\section{4 커뮤니케이션 활동성}

본 연구에서 커뮤니케이션 활동성은 수용자들의 커뮤 니케이션 행동을 설명하는데 있어서 이용자들의 SNS를 통한 커뮤니케이션의 능동성/적극성을 측정하기 위한 개 념으로 제시되었다. 커뮤니케이션 활동성 개념은 PR연구 의 상황이론에서 공중유형에 따른 커뮤니케이션 특징을 살펴보는데 사용하는 정보추구와 정보처리와 일맥상통하 는 개념으로 볼 수 있다. 이에 본 연구에서는 SNS의 이용 동기와 커뮤니케이션 행동 간의 관계를 설명하기 위한 개념으로 커뮤니케이션 활동성이라는 개념을 설정하였 다. 이를 통해 본 연구에서는 SNS 이용동기 요인이 이용 자들의 정보추구, 발신행동 등과 같은 커뮤니케이션의 능 동성에 어떻게 영향을 미치는가를 살펴보고자 하였다.

김관규·이순연[7]은 커뮤니케이션 발신행동의 정도를
측정하기 위한 항목으로 정보와 의견을 게재한다, 다른 사람의 정보와 의견 요청에 응답한다, 다른 사람들과 토 론한다, 다른 사람에게 정보와 의견을 요청한다, 카페주 제와 관련 없는 내용을 게재한다 등의 항목을 사용한 바 있다. 본 연구에서는 위의 측정 문항을 토대로 SNS를 통 해서 타인, 단체, 또는 기업과 얼마나 적극적으로 커뮤니 케이션을 하는가를 측정하기 위하여 위의 문항을 수정 보완하여 5 가지의 문항들을 사용하였다 $(\alpha=.709)$. 응답자 들의 커뮤니케이션 활동성에 대한 기술통계 분석결과, 전 반적으로 커뮤니케이션 활동성은 중앙값이 이하로 낮은 수준으로 나타났으나, 정보와 의견 공유에 대해서는 다소 적극적인 것으로 나타났다. 이와 관련된 본 연구의 연구 문제는 다음과 같다.

<연구문제 2> 커뮤니케이션 활동성에 영향을 미치는 SNS 이용동기는 무엇인가?

\section{5 미디어 인게이지먼트}

본 연구에서는 최근 들어 커뮤니케이션 효과를 보다 세밀하게 검토하기 위해 활용되어지는 인게이지먼트라는 개념을 가지고 SNS를 통한 커뮤니케이션 행동의 결과를 살펴보고자 하였다. 일반적으로 미디어 인게이지먼트는 특정 미디어에 몰입하는 것을 의미하나 본 연구에서는 $\mathrm{SNS}$ 를 통한 소통에 대한 몰입 또는 이해도의 개념으로 조작적 정의하였다. 오세성[8]은 인게이지먼트라는 개념 속에 관심(interest), 선호(preference), 관여(involvement), 집중(attention) 등의 요소들이 포함되어 있다고 설명하였 다. 에프론[9]은 미디어 인게이즈먼트를 특정 미디어에 몰입하는 것으로 설명하였다. 김현숙·이경렬[10]은 에프 론의 관점을 바탕으로 트위터 몰입도 차이에 따라 트위 터를 통해 획득한 정보에 인게이지먼트에 어떠한 차이가 
있는가를 살펴본 바 있다. 본 연구에서는 미디어 인게이 지먼트를 SNS를 통한 소통에 대한 몰입 또는 이해도로 파악하고, SNS 이용동기가 미디어 인게이지먼트에 어떠 한 영향을 미치는가를 살펴보고자 하였다. SNS 소통에 대한 몰입 또는 이해도에 관한 미디어 인게이지먼트 측 정문항은 김현숙·이경렬[10]이 사용한 4 개의 측정문항에 $\mathrm{SNS}$ 매체 특성 이해도 측정을 위한 항목을 3 개 더 추가 한 후, 연구의 목적에 맞게 수정 보완하여 사용하였다( $\mathrm{a}$ $=.762$ ). 이와 관련된 본 연구의 연구문제는 다음과 같다.

<연구문제 3> 미디어 인게이지먼트에 영향을 미치는 SNS 이용동기는 무엇인가?

\section{3. 분석결과}

\section{1 성별에 따른 SNS 이용동기 차이}

성별에 따른 SNS 이용동기에 대한 평균을 살펴본 결 과, SNS 이용동기는 [소통관계유지동기]가 가장 높았으 며, 다음으로 [정보지식획득동기], [의견정보제시동기]가 가장 낮은 것으로 나타났다. 성별에 따른 SNS 이용동기 의 차이를 T-검증을 통해 분석한 결과, [정보지식 획득동 기]와 [의견정보 제시동기]에는 남성과 여성간 통계적으 로 유의한 차이는 나타나지 않았다. 반면 [소통관계유지 동기]에서는 남성과 여성간 유의한 차이가 있는 것으로 나타났으며, 남성의 소통관계가 동기가 여성보다 높은 것 으로 나타났다.

[표 2] SNS 이용동기에 대한 $\mathrm{T}$ 검증 분석결과 [Table 2] T-test result of SNS use motivation

\begin{tabular}{|c|c|c|c|c|}
\hline 이용동기 & 성별 & 평균 & $\mathrm{t}$ & sig, \\
\hline \multirow{2}{*}{$\begin{array}{l}\text { 정보지식 } \\
\text { 획득동기 }\end{array}$} & 남 & 3.25 & \multirow{2}{*}{1.218} & \multirow{2}{*}{.226} \\
\hline & 여 & 3.05 & & \\
\hline \multirow{2}{*}{$\begin{array}{l}\text { 소통관계 } \\
\text { 유지동기 }\end{array}$} & 남 & 3.81 & \multirow{2}{*}{2.515} & \multirow{2}{*}{$.013^{*}$} \\
\hline & 여 & 3.45 & & \\
\hline \multirow{2}{*}{$\begin{array}{l}\text { 의견정보 } \\
\text { 제시동기 }\end{array}$} & 남 & 3.06 & \multirow{2}{*}{1.218} & \multirow{2}{*}{.226} \\
\hline & 여 & 2.84 & & \\
\hline
\end{tabular}

\section{2 커뮤니케이션 활동성에 영향을 미치는 이 용동기 요인}

커뮤니케이션 활동성 항목에 대한 기술통계량을 살펴 보면, '다른 사람(단체 또는 기업 포함)들과 토론/정보의 견요청 또는 개진 활동' 보다는 '정보와 의견의 공유/보 고 듣기'의 평균이 높은 것으로 나타난 것을 알 수 있었 다.
SNS 이용동기 요인이 커뮤니케이션 활동성에 미치는 영향을 다중회귀분석을 통해 살펴본 결과는 다음과 같다. 분석결과, [의견정보제시동기]와 [소통관계유지동기]는 커뮤니케이션 활동성에 유의한 영향을 미치는 것으로 나 타났으나, [정보지식획득동기]는 유의한 영향을 미치지 못하는 것으로 나타났다. SNS 이용동기가 커뮤니케이션

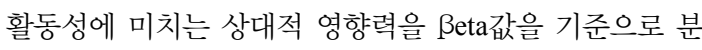
석한 결과, [의견정보제시동기]의 영향력이 [소통관계유 지동기]의 영향력보다 다소 큰 것으로 나타났다.

[표 3] SNS 이용동기가 커뮤니케이션 활동성에 미치는 영향 [Table 3] Influence of the SNS use motivation on communication activity

\begin{tabular}{ccccc}
\hline \multirow{2}{*}{ 구분 } & \multicolumn{5}{c}{ 커뮤니케이션 활동성 } \\
\cline { 2 - 5 } & $\mathrm{B}$ & $\beta$ & $\mathrm{t}$ & $\mathrm{sig}$ \\
\hline $\begin{array}{r}\text {-정보지식 } \\
\text { 획득동기 }\end{array}$ & .142 & .159 & 1.731 & .086 \\
-소통관계 & .194 & .205 & 2.204 & $.030^{*}$ \\
$\begin{array}{r}\text { 유지동기 } \\
\text {-의견정보 }\end{array}$ & .203 & .258 & 2.749 & $.007^{* *}$ \\
제시동기 & \multicolumn{5}{c}{.210} \\
\hline$R^{2}$ & \multicolumn{5}{c}{$9.396(.000)$} \\
$\mathrm{F}(\mathrm{p})$ & \multicolumn{5}{c}{} \\
\hline
\end{tabular}

\section{3 미디어 인게이지먼트에 영향을 미치는 이} 용동기 요인

미디어 인게이지먼트 측정 항목에 대한 기술통계량을 살펴보면, 'SNS를 통한 소통은 믿을 수 있다(평균 2.80)' 와 'SNS를 통한 소통은 신뢰가 간다(평균 2.76)' 의 두 항 목은 중앙값 이하의 부정적인 평균값을 보이는 것으로 나타났다. 반면 나머지 측정항목인 'SNS를 통한 소통은 실생활에 도움이 된다(평균 3.48)', 'SNS를 통한 소통을 통해 다양한 정보를 제공받을 수 있다(평균 3.91)', 'SNS 를 통한 소통은 유익하다(평균 3.75)', 'SNS를 통한 소통 은 이해하기가 쉽다(평균 3.62)', 'SNS를 통한 소통은 어 렵지 않다(평균 3.81)' 으로 긍정적인 것으로 나타났다. 미디어 인게이지먼트 측정을 위한 7개 항목에 대한 신뢰 도 분석결과, $a=.762$ 로 나타났으며 전체 평균은 3.45 점으 로 나타났다.

SNS 이용동기 요인이 미디어 인게이지먼트에 미치는 영향을 다중회귀분석을 통해 살펴본 결과는 다음과 같다. 분석결과, [정보지식획득동기]와 [소통관계유지동기]는 미디어 인게이지먼트에 유의한 영향을 미치는 것으로 나 타났으나, [의견정보제시동기]는 유의한 영향을 미치지 못하는 것으로 나타났다. 
$\mathrm{SNS}$ 이용동기가 커뮤니케이션 활동성에 미치는 상대 적 영향력을 ßeta값을 기준으로 분석한 결과, [정보지식 획득동기의 영향력이 [소통관계유지동기]의 영향력보다 상대적으로 더 높은 것으로 나타났다.

[표 4] SNS 이용동기가 미디어 인게이지먼트에 미치는 영향

[Table 4] Influence of the SNS use motivation on media engagement

\begin{tabular}{ccccc}
\hline \multirow{2}{*}{ 구분 } & \multicolumn{5}{c}{ 미디어 인게이지먼트 } \\
\cline { 2 - 5 } & $\mathrm{B}$ & $\beta$ & $\mathrm{t}$ & $\mathrm{sig}$ \\
\hline $\begin{array}{r}\text {-정보지식 } \\
\text { 획득동기 }\end{array}$ & .238 & .348 & 3.971 & $.000^{* * *}$ \\
$\begin{array}{r}\text {-소통관계 } \\
\text { 유지동기 } \\
\text {-의견정보 }\end{array}$ & .171 & .235 & 2.654 & $.009^{* *}$ \\
제시동기 & .080 & .132 & 1.471 & .144 \\
\hline$R^{2}$ & \multicolumn{5}{c}{.283} \\
$\mathrm{~F}(\mathrm{p})$ & \multicolumn{5}{c}{$13.971(.000)$} \\
\hline
\end{tabular}

\section{4. 결론}

본 연구에서는 SNS 이용동기 요인의 특징과 이용자들 의 커뮤니케이션 행동간의 관계를 살펴보고자 하였다. 분 석결과는 다음과 같이 정리되었다. 첫째, $\mathrm{SNS}$ 의 이용동 기는 크게 정보지식획득을 위한 동기, 소통관계 유지를 위한 동기, 의견정보제시를 위한 동기요인으로 구분되는 것으로 나타났다. 전반적으로 남성의 SNS 이용동기가 더 높게 나타났으며, 소통관계유지동기요인에서는 남성과 여성간 유의한 차이가 있는 것으로 나타났다. 둘째, SNS 이용에 있어서 응답자들은 토론/정보나 의견의 요청 또 는 개진과 같은 적극적인 정보 추구 활동보다 $\mathrm{SNS}$ 를 통 해 정보나 의견의 공유 또는 보고 듣기와 같은 정보 처리 활동 경향이 다소 높은 것으로 나타났다. 더 나아가 [의 견정보제시동기]나 [소통관계유지동기]는 커뮤니케이션 활동성 전반에 긍정적인 영향을 미치는 것을 알 수 있었 다. 반면 [정보지식획득동기]는 커뮤니케이션 활동성에 유의한 영향을 미치지 않음을 알 수 있었다. 이를 놓고 볼 때, SNS 이용자의 커뮤니케이션 행동은 아직까지 정 보처리 행동 경향이 높다고 판단된다. 단 이용자들의 의 견정보제시 또는 소통관계를 목적으로 $\mathrm{SNS}$ 를 이용할 경 우에는 적극적으로 정보 추구행동을 보일 것으로 판단된 다. 셋째, 응답자들의 SNS에 대한 미디어 인게이지먼트 는 $\mathrm{SNS}$ 를 통한 소통이 실생활에 도움이 되고, 다양한 정 보를 제공받을 수 있고, 유익하며 이해하기 쉽고 어렵지
않다는 측면에서 긍정적인 인식을 가지고 있는 것으로 나타났다. 반면 SNS를 통한 소통에 대한 믿음과 신뢰는 다소 부정적인 것으로 나타났다. 더 나아가 이러한 SNS 에 대한 전반적인 미디어 인게이지먼트에는 SNS의 이용 동기 중에서 [정보지식획득동기]와 [소통관계유지동기] 는 긍정적인 영향을 미치는 것으로 나타났으나 [의견정 도제시동기]는 유의한 영향을 미치지 않는 것으로 나타 났다. 이러한 연구결과들은 향후 기업 커뮤니케이션 관점 에서 SNS 이용자들의 이용동기를 이해하고 이용동기에 따라 이용자들의 커뮤니케이션 행동이 어떻게 나타나는 가를 이해하는데 시사점을 제공하고 있다.

\section{References}

[1] Kim, H. S. and Yu, H. J.: In Social Media Days, A Study on a communication Strategy of Corporate CEO, Advertising Research, Vol. 87(winter), pp.303-338, 2010.

[2] Rubin, A. M.: Ritualized Instrumental Television Viewing, Journal of Communication, 34(3), pp.67-77, 1984.

[3] Lee, S. B. and Kim, N. L.: The Effect of Public Lifestyle on Motivation and Behavior Using Social Media, Korean Journal of Advertising and Public Relations, Vol. 13(2), pp.306-341, 2011.

[4] Yun, S. U.: Study on the Effect of Twitter User's Use Motive on the Emotional Connectedness, Awareness of Co-space, Reliability of information and emotional intimacy, Political Communication Research, Vol. 22(2), pp.131-170, 2011.

[5] Shim, H. J. and Hwang, Y. S.: Micro-blogging on Uses and Gratification Perpectives, Korean Journal of Broadcasting \& Telecommunication, Vol. 24(2), pp.192-233, 2010.

[6] Kim, B. H. and Han, S. P.: The Exploratory Factor Analysis for Assessing Television Commercials' Creativity, The Korean Journal of Advertising, Vol. 18(5), pp.257-272, 2007.

[7] Kim, K. K. and Lee, S. Y.: Effect of User's Personal Characteristics on Sending Behavior of Information and Opinion in Interactive Public Communication Space of CMC, Journalism Science Research, Vol. 5(3), pp.5-34, 2005.

[8] Oh, S. S.: Study about Influence on BrandADpower Recognition of TV Advertising by Broadcating Advertising Selling Method based Program Engagement, 
KOBACO Research Paper, 2008.

[9] Ephron, E., "Want Engagement? make a more engaging AD.", http://www.ephrononmedia.com/article_archive/ articleViewerPublic.asp?articleID $=148$

[10] Kim, H. S. and Lee, K. Y.: Effects of Twitter Users' Innovativism, Needs for Social Capital, and Self Consciousness on Twitting Patterns and Information Engagement, Advertising Research, Vol. 89(summer), pp.122-154, 2011.

김 형 석(Hyung-Suk Kim)

[정회원]

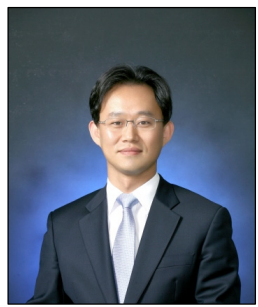

- 2000년 2월 : 한양대학교 광고홍 보학과(광고홍보학 석사)

- 2007년 8월 : 한양대학교 광고홍 보학과(홍보학박사)

- 2009년 3월 2010년 2월 : 한 양대학교 광고홍보학과 조교수

- 2010년 3월 현재 : 청운대학 교 광고홍보학과 전임강사

<관심분야>

$\mathrm{PR}$ (홍보), 설득커뮤니케이션, 뉴미디어(SNS) 